\title{
High Speed Machining (HSC) of Sculptured Surfaces in Die and Mold Manufacturing
}

\author{
Thorsten Finzer (finzer@ptw.tu-darmstadt.de) \\ Darmstadt Universtiy of Technology, Germany
}

Key words: High speed machining, die and mold manufacturing, cutting strategies

Abstract: In order to use the next generation of high-speed machine tools economically, first of all the technological background of the best machining strategies has to be found out. For this purpose four approaches in the machining process have to be made simultaneously. These approaches are the optimization of the machining parameters, the choose of the right cutting edge material and cutting tool and the use of proper machining strategies. The economic application of the best milling strategies depends on the dynamic capabilities of the machine tool. Therefore, machines with linear motor drives will become more and more important for die and mold production.

\section{INTRODUCTION}

High speed cutting has many principal advantages. By increasing the cutting speed it is possible to reduce the cutting forces, to dissipate process heat completely with chip removal, to generate better surfaces, to increase the metal removal rate and to perform machining in a range of uncritical vibration. The cutting speed mainly depends on the work-piece material.

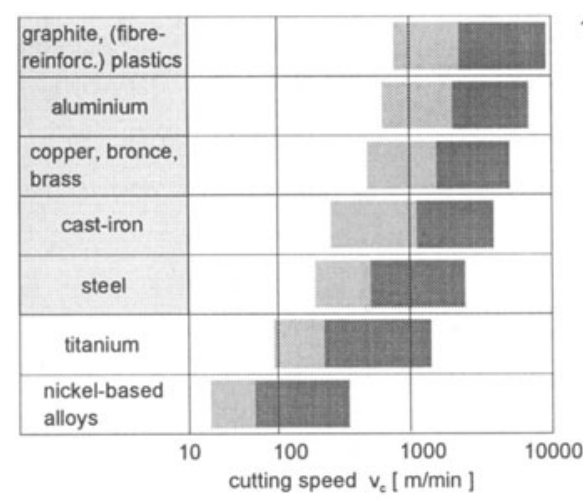

transition area

HSC-area

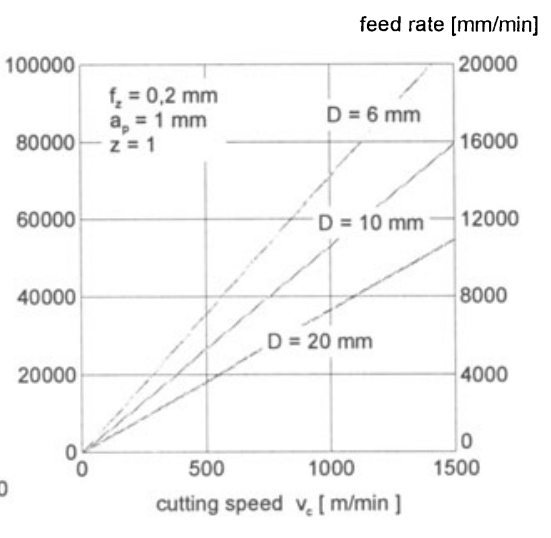

calculated with maximum

diameter in use

Figure 1. Definition of HSC in die and mold manufacturing

But more important than the increase of cutting speed is the increase of feed rate. Therefore, especially in the field of die and mold manufacturing using small tool diameters for machining sculptured surfaces, high spindle frequencies in combination with high feed rates are a more precise characterization for HSC (Fig. 1). Besides the importance of manufacturing time and surface quality, there is in particular a considerable reduction of costs. These results can be seen in many application fields and the most important among these are

The original version of this chapter was revised: The copyright line was incorrect. This has been corrected. The Erratum to this chapter is available at DOI: 10.1007/978-0-387-35392-0_40 
dies and molds, aerospace parts and critical thin-walled components susceptible to heat distortion.
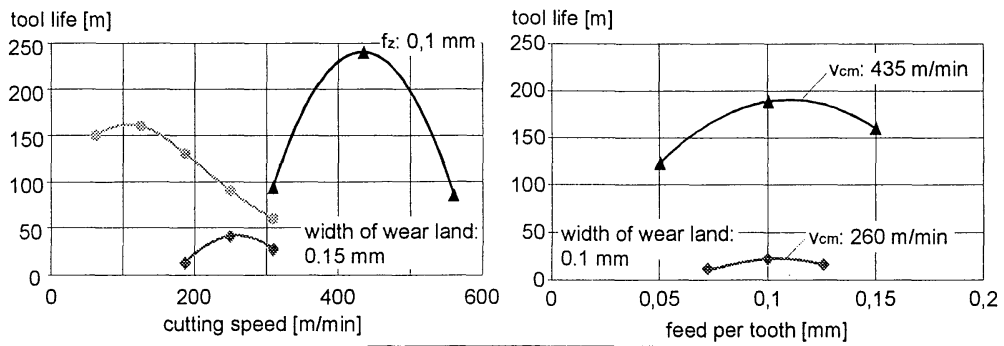

$$
\begin{aligned}
& \star \text { CBN } \\
& \text { - Solid carbide (TiN-coated) } \\
& \text { - Cermet }
\end{aligned}
$$

workpiece:

X100CrMoV51 (2363) 60 HRC tool:

\section{ball head: $\varnothing 6 \mathrm{~mm}$}

number of teeth: 2 (CBN: 1)

cutting material: solid carbide (TiN),

CBN, Cermet

overhang: $24 \mathrm{~mm}$ (CBN: $30 \mathrm{~mm}$ )

feed per tooth [mm]

technology:

up-cut/reverse-cut

tilting angle: +15

cutting depth: $0.1 \mathrm{~mm}$

line space: $0.2 \mathrm{~mm}$

Figure 2. Tool life dependent on machining parameters

\section{IMPROVEMENT OF THE MACHINING PROCESS}

The only disadvantage of HSC is tool life reduction caused by increasing cutting speed. In order to reach an economic application in die and mold manufacturing this disadvantage has to be solved. Therefore, four approaches can be taken which should be carried out simultaneously:

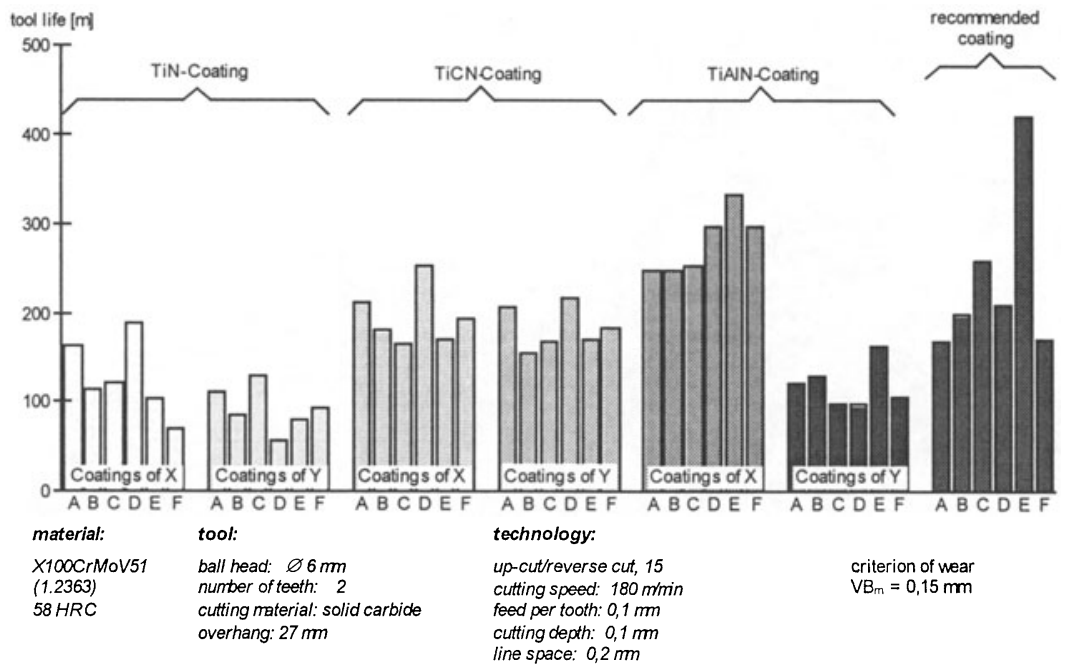

Figure 3 Different cutting tool materials and coatings 


\subsection{Optimization of the machining parameters}

In high speed machining the range of optimum wear performance is relatively small. So it will be required to determine the optimum machining parameters for each application, each workpiece material and each cutting material (Fig. 2).
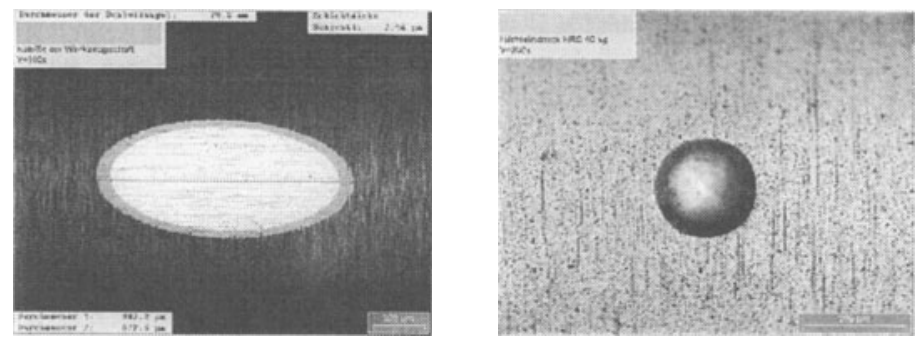

"good"
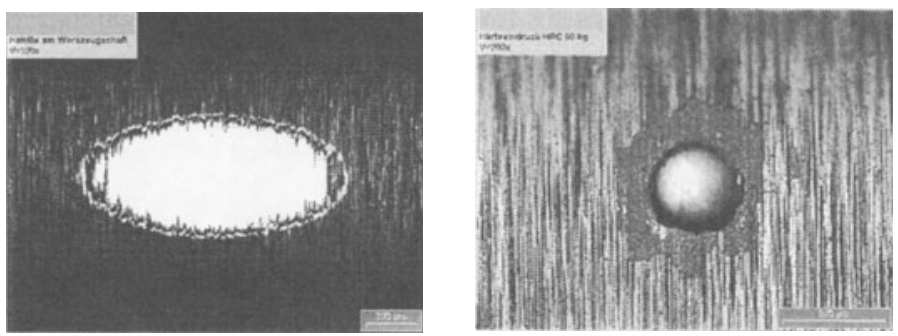

"poor"

Figure 4 Result of optimal and deficient coating process
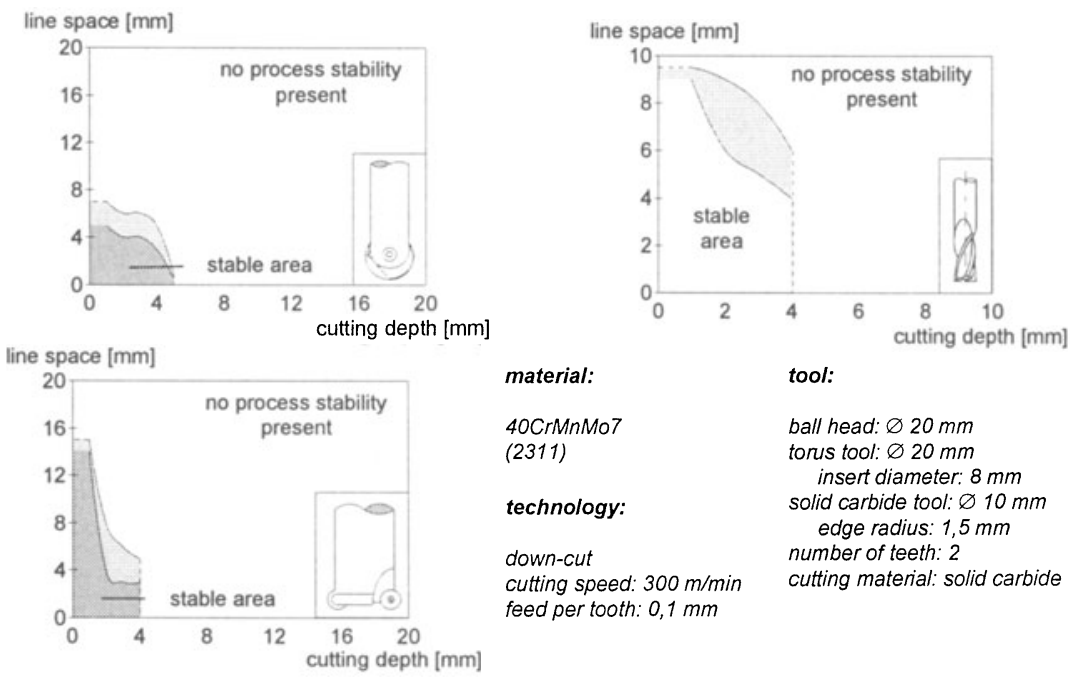

material:

40CrMnMo7 (2311)

technology:

down-cut

cutting speed: $300 \mathrm{~m} / \mathrm{min}$ feed per tooth: $0,1 \mathrm{~mm}$ tool:

ball head: $\varnothing 20 \mathrm{~mm}$ torus tool: $\varnothing 20 \mathrm{~mm}$ insert diameter: $8 \mathrm{~mm}$ solid carbide tool: $\varnothing 10 \mathrm{~mm}$ edge radius: $1,5 \mathrm{~mm}$ number of teeth: 2 cutting material: solid carbide

Figure 5. Maximum allowed infeeds (application limits)

\subsection{Right cutting edge material}

The choice of the proper cutting material is of utmost importance for tool life. While, for instance, $\mathrm{CBN}$ will furnish optimum values in machining cast iron, using this cutting material 
on heat-treated steel will lead to completely unsatisfactory results. Even when using the same cutting material, it is possible to get differences up to factor 10 in tool life. Also coatings have a big influence in tool life of cemented carbide (Fig. 3). Using the best combination of substrate plus coating is the base for an efficient and economic cutting process. A deficient coating due to wrong parameters in the coating process or wrong combination of substrate / coating will lead to insufficient and unpredictable tool life (Fig 4.).
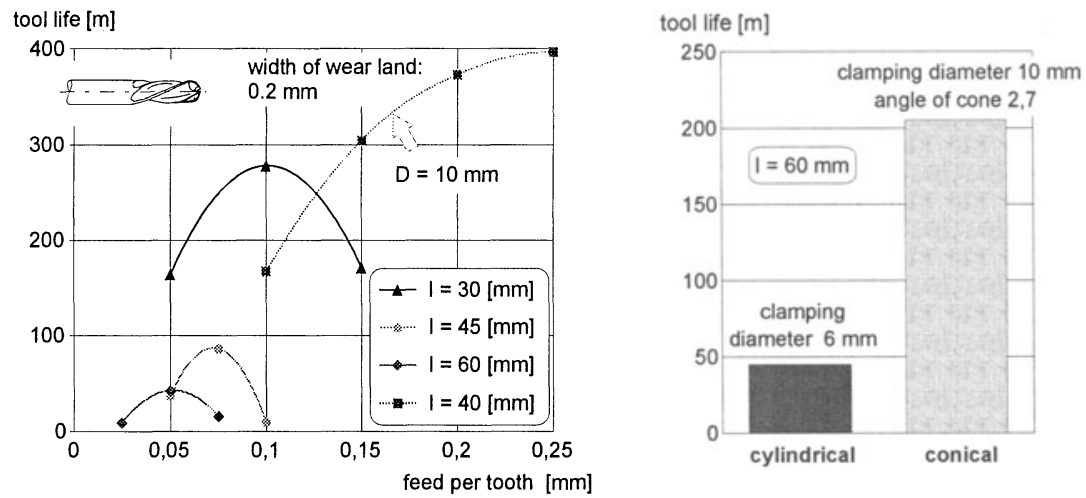
material:
tool:
technology:
40 CrMnMo7 ball head: $\varnothing 6 \mathrm{~mm}$
(2311) number of teeth: 2
down-cut/reverse-cut, 15
number of teeth: $2 \quad$ cutting speed: $300 \mathrm{~m} / \mathrm{min}$
cutting material: Cermet feed per tooth: $0.05 \mathrm{~mm}$ (cylindr.), $0.1 \mathrm{~mm}$ (conical)
resp. solid carbide cutting depth: $0.5 \mathrm{~mm}$
overhang: $60 \mathrm{~mm}$
line space: $0.5 \mathrm{~mm}$

Figure 6 Influence of tool overhang on tool life resp. process stability

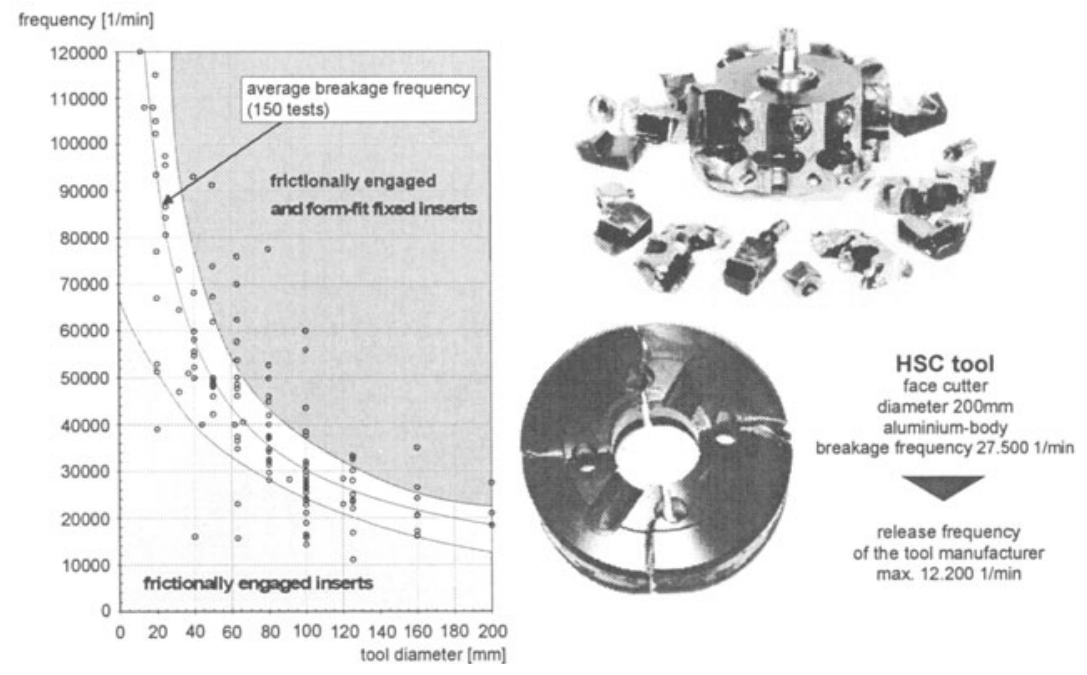

Figure 7. Cutting tools - max. frequencies 


\subsection{Right cutting tool}

The field of process stability strongly depends on the dynamic performance of the tool (Fig. 5). Due to the high tool loads and the close limits of stability in high speed milling, the knowledge of the optimum technological and strategic parameters is of utmost importance. Also highly relevant for the tool life is the geometry of the cutting edge and the clamping length of the tool (Fig. 6).

Another important point for tools used in HSC is their capability to resist centrifugal forces and a small amount of unbalanced masses. When using the wrong tool, high spindle frequencies can lead to tool breakage. A released insert has the kinetic energy of a gun bullet. Correlated with this, HSC-machine tools should be equipped with bullet proofed glass to reduce damage (Fig. 7).

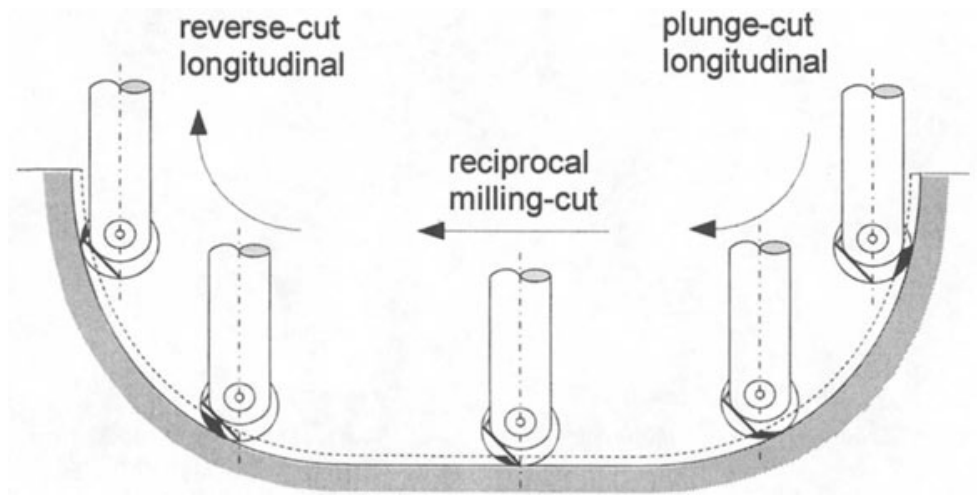

Figure 8. Use of different cutting strategies

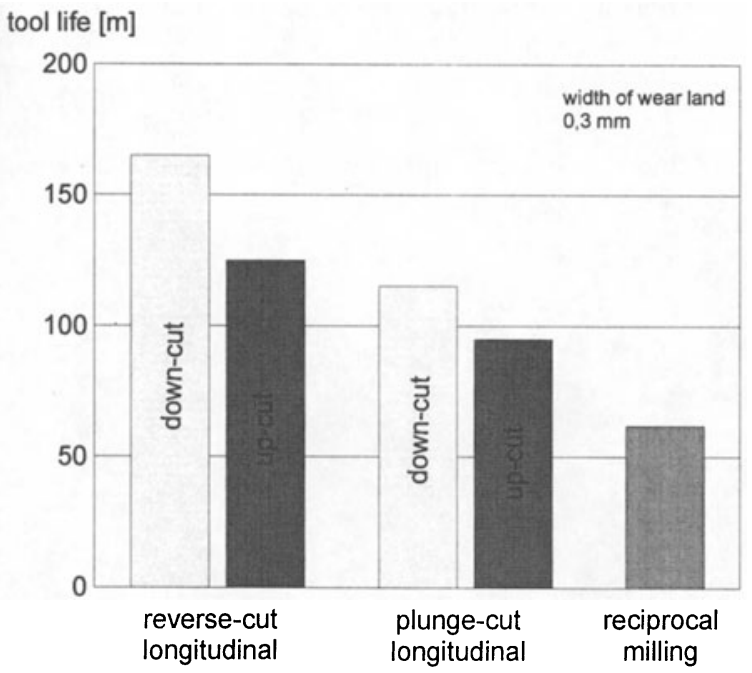

material:

40 CrMnMo7

(2311)

tool:

ball head: $\varnothing 20 \mathrm{~mm}$

number of teeth: 1

cutting material: solid carbide (TiN)

overhang: $60 \mathrm{~mm}$

technology:

tilting angle: $+/-15$

cutting speed: $300 \mathrm{~m} / \mathrm{min}$

feed per tooth: $0.3 \mathrm{~mm}$

cutting depth: $1 \mathrm{~mm}$

line space: $0.7 \mathrm{~mm}$

Figure 9. Effect of different milling strategies on tool life 


\subsection{Proper machining strategy}

The highest influence on the improvement of tool life is achieved by the choice of the optimal cutting strategy. Mold elements of sculptured surfaces can be generated in various ways, such as by up-cut or down-cut machining and also by reverse, plunge or reciprocal cut (Fig. 8).

By applying the proper combinations substantial increases in tool life and also improved surface quality can be achieved (Fig. 9). Additionally, different strategies cause different dimensional accuracy (Fig. 10). Therefore, it is obvious that the strategy has an enormous influence on the machining result and also on the quality of the mold and the economy of machining.
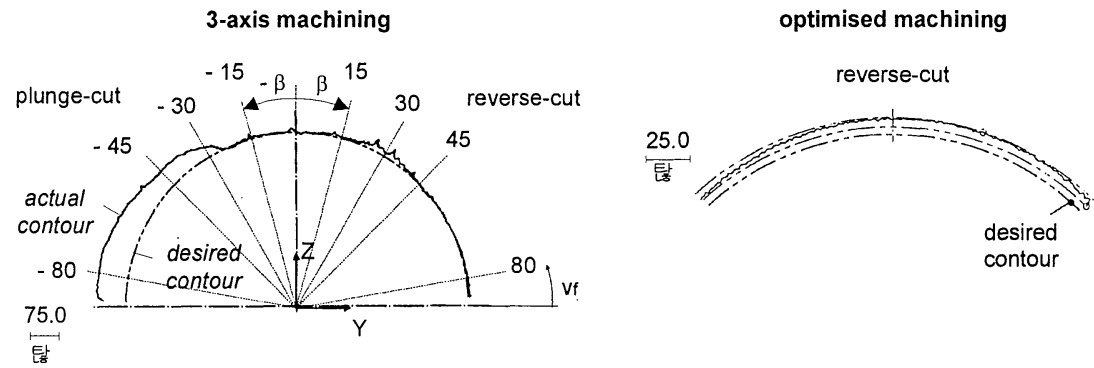

$$
\begin{array}{ll}
\text { material: } & \text { tool: } \\
\text { 40CrMnMo } & \text { insert miller } \\
\text { (2311) } & \text { ball head: } \varnothing 20 \mathrm{~mm} \\
\text { convex } R=36 & \text { number of teeth: } 2 \\
& \text { cutting material: Cermet } \\
& \text { overhang: } 70 \mathrm{~mm}
\end{array}
$$

technology:

turning frequency: $113001 / \mathrm{min}$

feed per tooth: $0.1 \mathrm{~mm}$

cutting depth: $1 \mathrm{~mm}$

line space: $0.7 \mathrm{~mm}$

Figure 10 Effect of different milling strategies on accuracy

\section{FAST MACHINE TOOLS}

Always working with optimal conditions results into an increasing amount of idle time. In this case standard CNC-machines cannot be used economically. 


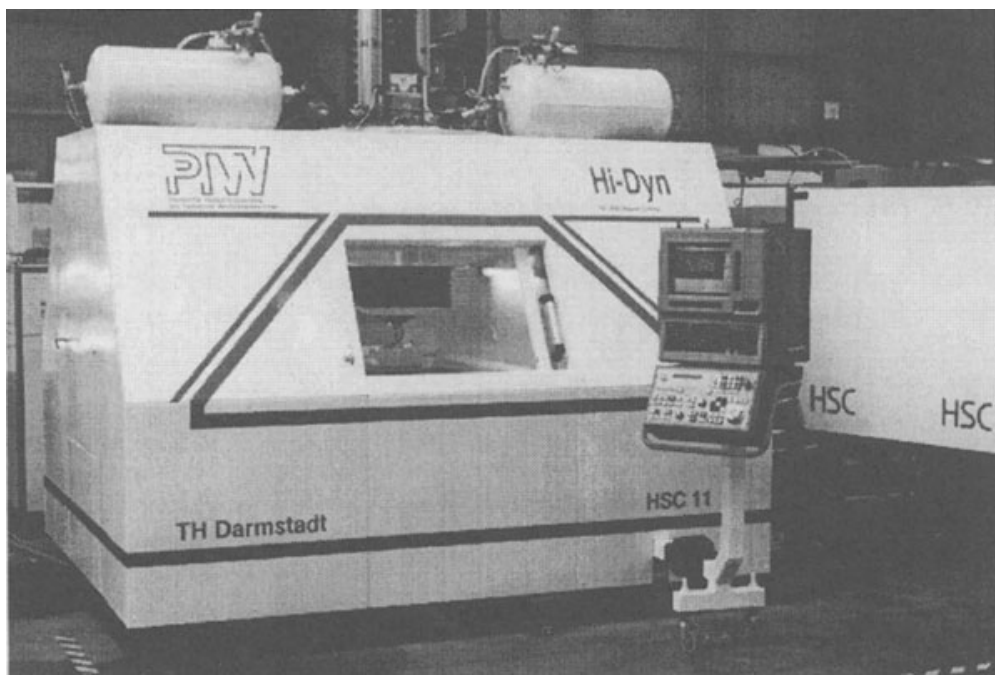

Figure 11. Highly dynamic 3-axis milling machine with linear feed drives

Therefore, the machines will have to be even faster, more dynamic, more powerful and more accurate. To achieve this, an innovation leap is required, such as a linear motor machine tool (Fig. 11).

This machine tool will permit axis accelerations up to $25 \mathrm{~m} / \mathrm{s}^{2}$ and velocity gain up toKV=20-30 (m/min)/mm (300-500 sec-1). This will result not only in a considerable reduction of idle time. But also in better contour accuracy in machining complex dies and molds as a consequence of fast acceleration. E. g. dynamic travel accuracy is approximately 5 $\mathrm{mm}$ at a constant travel feed of $20 \mathrm{~m} / \mathrm{min}$.

The comparison between a machine tool with linear motor feed drives and one with roller ball drives shows tremendous reductions of machining time (Fig. 12).

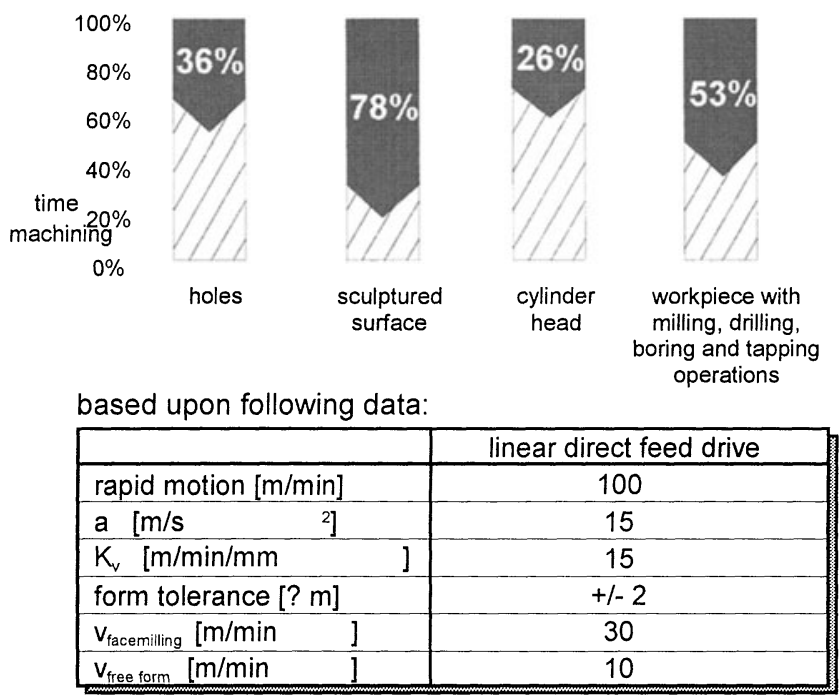

Figure 12. Reductions of machining time by using machine tools with linear feed drives 

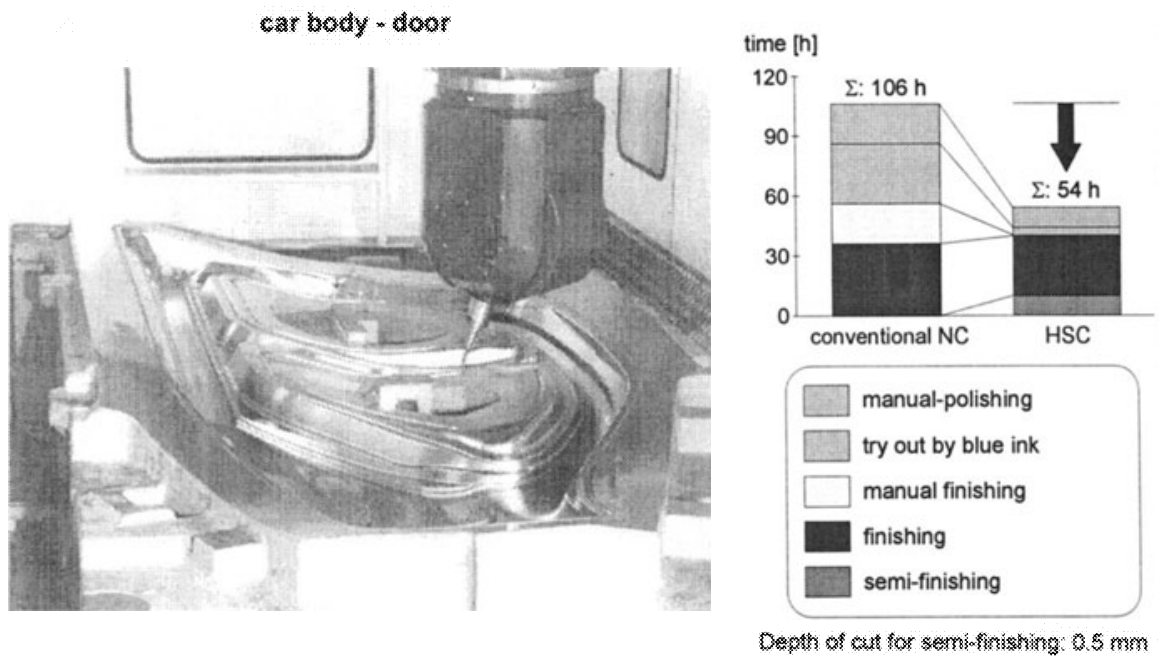

Figure 13. Advantages of HSC in die and mold manufacturing (source: Droop \& Rein)

\section{CONCLUSIONS}

When considering the whole chain of the manufacturing process, by the very high surface qualities generated by HSC in many cases subsequent finish operations, e. g. grinding, can be eliminated. In die and mold manufacturing, for instance, machined sculptured surfaces are very close to the required final shape accuracy. This will reduce manual rework time considerably. Time savings up to $80 \%$ and cost savings up to $30 \%$ are quite realistic. The two following examples show the potential of HSC (Fig. 13, 14).

In order to achieve better tool life, high accuracy and additional shorter time it is necessary to use very fast and dynamic machine tools.

Finally, the developments in HSC and in the involved fields are still continuing. The next improvements are predictable and mark the current trends in the four fields machining process, cutting material / coating, machine tool / components and NC (Fig.15).
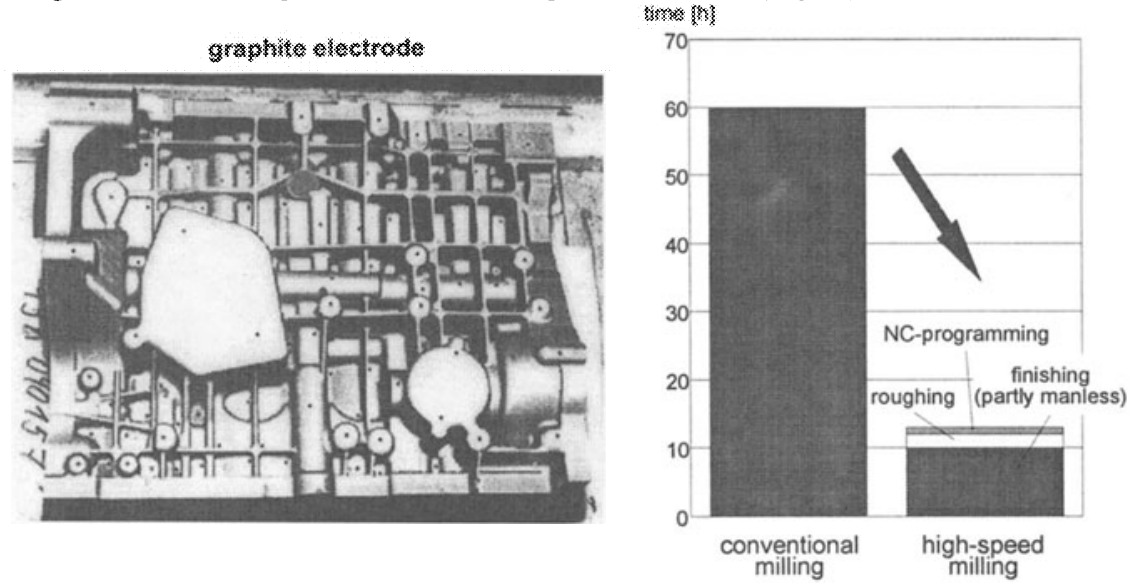

Figure 14. Advantages of HSC in die and mold manufacturing (source: Volkswagen) 

$\star$ process:
$\rightarrow$ new workpiece materials
(4) machining hardened steel, dry-machining
$\rightarrow$ higher process stability
* cutting material / coating: $\quad$ th optimised preconditioning and coating process
(4) optimisation of substrate / coating
(5) new coatings (Ytrium, Vanadium)
$\star$ machine tool / components: $\stackrel{4}{\rightarrow}$ dynamic feed drives, parallel mechanism
a) HPHF-spindle
$\star \mathrm{NC} /$ interfaces: $\quad \Leftrightarrow \quad$ data management (EDM / PDM), WOP
(4) automation, information tools
(4) no NC-Codes DIN 66025 (Splines)

Figure 15. Trends in high speed machining

\section{REFERENCES}

1 Finzer, Th., "High Speed Machining (HSC) In Die and Mold Manufacturing", $2^{\circ}$ Seminario Internacional de Alta Tecnologia, Piracicaba, Brasil, 1997

2 Schulz, H., "Hochgeschwindigkeitsfräsen metallischer und nichtmetallischer Werkstoffe (over 200 refer-ences inside)", Carl Hanser Verlag, München, Wien, 1989, ISBN 3-446-15589-9

3 Schulz, H., "Hochgeschwindigkeitsbearbeitung - High-Speed Machining (over 300 references inside)", Carl Hanser Verlag, München, Wien, 1996, ISBN 3-446-18796-0

4 Zirn, O., Weikert, S., Rehsteiner, F., "Design and optimization of fast axis feed drives using nonlinear stability analysis", CIRP-Annals, Volume 46/1/97: p. 363-366

5 Heisel, U., Gringel, M., "Machine tool design requirements for high speed machining", CIRP-Annals, Volume 46/1/97: p. 389-392 